\title{
Original Article \\ Visual evaluation of urban streetscapes: How do public preferences reconcile with those held by experts?
}

\author{
Morten Gjerde
}

School of Architecture, Victoria University of Wellington, PO Box 600, 139 Vivian Street, Wellington, New Zealand.

E-mail:Morten.Gjerde@vuw.ac.nz

\begin{abstract}
Visual qualities of well-liked settings are known to include richness and variety, tempered by perceptible underlying structure and clear associational meanings. For a variety of reasons - among them, technological, economic and professional principles - the design coherence of the built environment appears to have diminished in the wake of Modernism. However, opinions about the quality of the built environment are usually voiced by experts. Does it follow that their opinions are also those of lay people? Indeed, looking beyond academic critique of the appearance of the built environment, what are the views and aesthetic preferences of those who use the city? The article reports on the results of recent research that has evaluated perceptions of and preferences for a range of different urban street scenes. The opinions of the lay public as well as design and planning professionals have been collected for comparison. The research seeks to understand whether there are built-form characteristics, seen across a collection of buildings that make up a street edge, that are preferred over others. Based on data from 200 survey responses and a focus group discussion, the findings identify characteristics that are deemed to foster well-liked urban settings as well as those that should be avoided.
\end{abstract}

URBAN DESIGN International advance online publication, 6 July 2011; doi:10.1057/udi.2011.10

Keywords: environmental aesthetics; streetscape; design guidance; townscape

\section{Introduction}

With the notable exceptions of death and taxes, it is often said that there is nothing more certain than change. Change helps ensure continued viability and vitality of virtually every man-made and natural system. In urban environments, change is considered the lifeblood of economic, social and political systems that underpin society as well as of the built fabric that accommodates and facilitates activity (Dovey, 2001). The city is never considered to be complete and details at every morphological level are in constant flux (Lynch, 1960). Unfortunately, the changes that have been transforming many contemporary cities are not always viewed positively. Although some people, particularly those who enjoy financial or political gain in the process, may see discrete changes favourably, the vast majority of citizens are united in their dislike of the overall appearance of cities as they have transformed in recent years. Bentley (1999) describes a number of economic and cultural factors that help strip substance and visual quality out of the fabric of buildings before they are built or that cause the design of each new intervention to seek attention. As a consequence, these buildings are anything but well mannered and often they fail to develop even a fleeting relationship with those around them.

One of the strongest cultural imperatives in the redevelopment process flows through the architectural profession, which, reinforced by education, professional development and media agendas, privileges the architectural object over architectural manners. Nowhere are these tendencies more evident than in schools of architecture and in the various professional awards programmes. Professional and popular media also communicate the profession's - and by association, their client's - preferences for innovation and daring when it comes to form making. 
Designers with the highest profiles are those with portfolios featuring unique sculptural designs, not those who have learned to 'cultivate the field', the term used by Habraken (1994) to describe traditional patterns of mainly backcloth buildings prevailing in well-liked places. It seems that economic imperatives and professional attitudes that influence the shape of contemporary towns and cities have not always been sympathetic to the inescapable nature of the built environment. The aggregate of multiple, powerful architectural statements in a single setting can lead to visual cacophony (Smith, 1977) and the generally uninvolved public has had to bear the brunt of environments that have poor visual qualities (Carmona and Tiesdell, 2007).

This article examines the visual effects that result from contemporary urban transformation practices. At one end of the townscape spectrum are monotonous settings arising through redevelopment of large sites, often assembled to provide for economies of scale, and designed in a comprehensive manner. These are the environments criticised by Jane Jacobs (1961) for being sterile and uninviting. At the other end of the spectrum is a discordant chaos resulting from buildings designed in isolation, where each seeks to be the centre of attention. Rest assured this is a serious matter, as the appearance of the physical environment is not simply an abstract aesthetic phenomenon; we are becoming increasingly aware of the role that distinctive and welldesigned streetscapes play in creating positive mental images and place identity (Lynch, 1960; Carmona and Heath et al, 2010). The perceived quality of a setting depends on the evaluations of those who regularly experience it (Sanoff, 1991; Nasar, 1998).

Having recognised that the appearance of urban areas is diminished as a consequence of the contemporary development practices, many local authorities now control design as part of the planning approval process. However, throughout the design and review of new development proposals, attention is focussed on the new intervention. That is to say, the first consideration is whether the building is of a suitable standard, irrespective of the setting (RFAC, 1994). Once that condition is satisfied, the relationship with the context is probed, asking the question, 'Will this project fit here?' (RFAC, 1994; CABE, 2006). Perhaps the more appropriate questions might be 'what are the built-form characteristics that this setting demands?'
Those who are in positions to ask these questions during design review, and indeed who should be asking them as part of the design process, generally have some expertise in aesthetic judgement. We know it is in the culture of designers to favour visually innovative and distinct solutions, but this may arise as a consequence of the normative theories that inform practice. Are there really fundamental differences between experts and non-experts in the way they view and judge the everyday environments around them? If so, and this has been suggested in earlier studies (see for example Groat, 1994; Stamps, 1999; Fawcett and Ellingham et al, 2008), then expert-led design review processes must be called into question. What are the chances that change will lead to places that are well liked if the views of the vast majority of people are not represented?

\section{Research Design}

This research addresses two questions that hover around the edges of architectural design and design control of building projects in urban areas. First, do people have a preference for particular visual characteristics in urban streetscapes and, if so, what are they? This two part question is inspired by Bentley's (1999) contention that people are generally dissatisfied by the way cities have been changing. Although this aspect of the research does not seek to test the veracity of Bentley's claim, it does attempt to understand the bases on which their views might be formed. The second question addresses the vexed issue of expert opinion and particularly whether experts differ in their judgement of the typical urban streetscapes that have the most significant impact on people's experience of the cities and where the majority of change happens. Although Punter (1999) cautions design policymakers and controllers to be mindful that they are entrusted to represent the interest of the public, to what extent is it reasonable to expect that their own preferences are set aside to advocate for others when judging contextual suitability?

Although subjectivity and bias in aesthetic judgement of the built environment underpin motivation for this research, these issues are not addressed directly in the research design. Instead, the research seeks to identify if there are any areas of common ground in preference expressed by lay people and professional groups. Earlier studies 
have touched on this issue, but these have all focussed on single buildings, where preferences for certain architectural styles have been examined, or on the suitability of fit by a single building into a setting. Taking a slightly different tack, this research seeks to understand preferences for an entire group of buildings when read as a whole. By backing off from a focus on any one individual building, the relationships between all buildings can be considered. By taking a broader, less-focussed view, the valued characteristics extending across a collection of buildings may be revealed. This knowledge can then help direct efforts to strengthen positive visual characteristics with each intervention rather than simply asking whether a development proposal will fit in.

It was determined that a survey would be conducted to enable people's aesthetic preferences to be understood by way of objective data analysis. Six different urban streetscapes, illustrated in Figure 1, were presented to respondents in the form of photographic elevations. The use of computer software would have enabled virtually any design relationships to be created artificially, but real scenes were required to provide for future research to be undertaken in conjunction with the study reported on here. The author is an experienced design reviewer and scenes were selected to test perceptions of certain troublesome design relationships that have been emerging in practice. In particular, examples of a large-scale intervention into an underlying fine grain pattern (Scene 1), of consistency (Scenes 2 and 6) and differences (Scene 3) of building heights, of a single large development extending over a whole block (Scene 4), of poor pedestrian-level interface (Scene 5) and of a strongly consistent pattern (Scene 6) were sought.

Although it is clear that experience of the built environment is four-dimensional, previous research (Groat, 1988; Nasar, 1998; Stamps, 2000) has found a relative correlation between preferences expressed in response to two-dimensional photographic images and preferences expressed in the field. That is to say, relativity between preferences expressed in response to two-dimensional photographic images correlates strongly to the relativity between preferences expressed by people who visit and spatially experience the same scenes. Knowledge of this gave the author confidence to employ photographic representation as a means of gauging preferences for particular design scenarios, not all of which would be found in one city. Extending the techniques used by Portella (2007) in her investigation of responses to urban signage, individual buildings were photographed digitally and stitched together to create an accurate elevation of each scene. Photoshop ${ }^{\mathrm{TM}}$ software was used to correct the perspective of each image and to stitch the individual images. Communication of the three-dimensional qualities of each scene was enhanced by also providing respondents with a perspective view taken from each end (Figure 2).

To enable people's perceptions to be correlated to specific characteristics of the scene, a tool to measure the characteristics was developed. After canvassing a number of options, the method developed by Reeve et al (2007) in their longitudinal evaluation of townscape provided a starting point. Designed for use by an expert in the field, the tool builds up a rating for a particular scene under five headings described in the analytical framework. A 10-point scale enables greater distinction between the numeric values generated. The survey questionnaire was developed around the same list of design characteristics but refined to communicate design concepts to a lay audience. Respondents were asked to rate their overall preference for certain design attributes, such as colour and building heights, to rate the scene as a whole and then to identify any buildings that did not fit. Following initial analysis of the survey responses a focus group was convened to further tease out the reasoning that lay behind certain responses.

\section{Analytical Framework}

Literature in the fields of aesthetics, environmental psychology and urban design was consulted and a framework to guide the research developed. Cuthbert (2006) indicates that an aesthetically pleasing experience is one that provides pleasurable sensory experiences, a pleasing perceptual structure and pleasurable symbolic associations. This definition provides a useful guide to the different levels of aesthetic perception that are necessary to be able to judge a scene or setting. Aesthetic experience is conceptualised to occur on three levels: sensory perception, cognition and meaning.

The two most important formal factors affecting judgement are order and visual interest tending towards ambiguity and complexity (Rapoport and Kantor, 1967; Nasar, 1994). Gestalt psychology helps us to understand the innate 

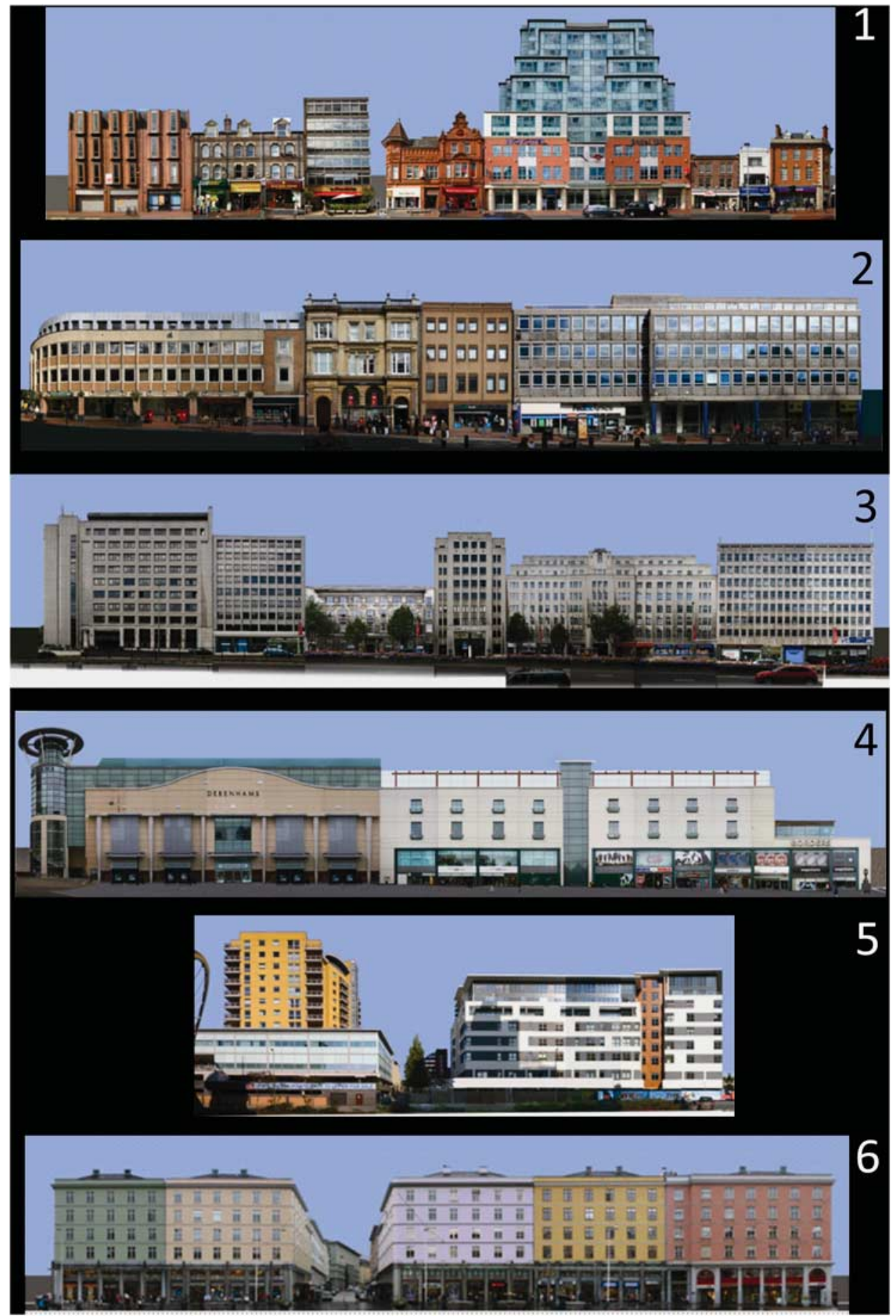

Figure 1: The six urban street scenes used to stimulate responses to various built-form characteristics in the research.

human desire to resolve visual stimuli into ordered patterns. Coherence of overall building shape, patterns developed in building facades and strong compositional elements such as street verandahs typical in Australasian cities are but some of the formal characteristics that can enhance sense of order in a scene. Stimulation of interest must be managed to ensure the mind is not taxed in visual perception. Nasar (1994) notes that moderate stimulus levels will generate positive aesthetic experience until reaching a level where pleasure begins to diminish. 


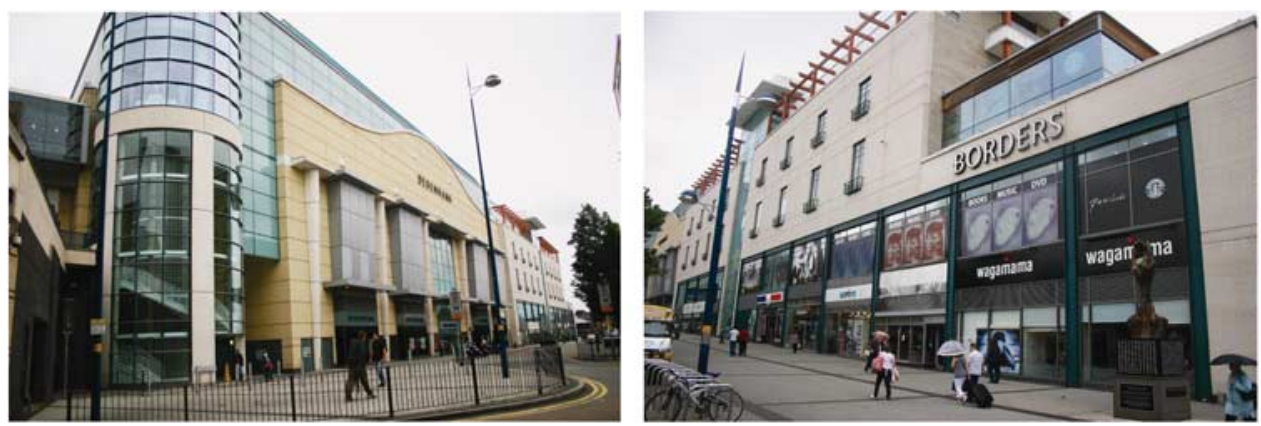

Figure 2: Perspective views were provided with the elevation views for each of the six scenes. These views relate to Scene 4.

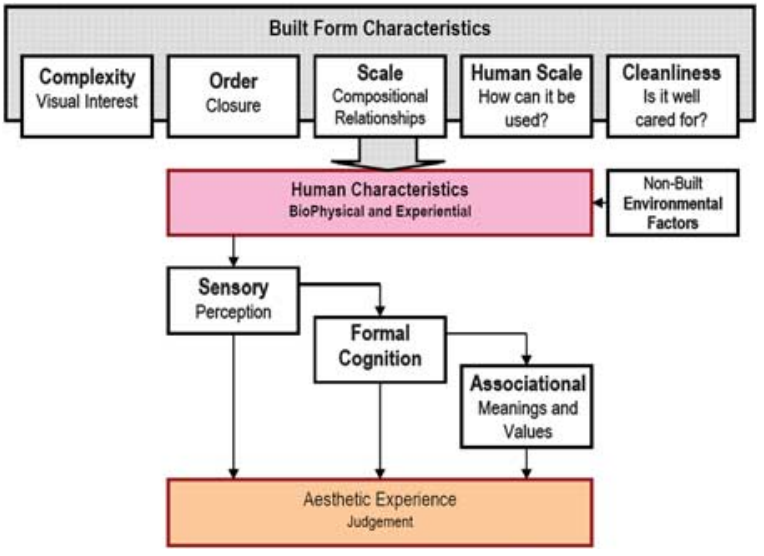

Figure 3: The framework around which the research methodology revolved. These design characteristics that influence aesthetic perception informed the survey questionnaire and the streetscape analysis tool.

Powerful meanings attach to the way we understand the environment or a building to be used. Not only do people evaluate the nature of the activities they understand to take place within, they are also influenced by the degree to which they can imagine themselves able to participate in those activities. Therefore, public buildings can have very positive associational meanings for many people. Construction materials, standard of detailing and standard of maintenance can convey messages about the status of the building owner or the way a building would feel to be inside (Alcock, 1993). The analytical framework is outlined as shown in Figure 3.

\section{Findings and Discussion}

The survey returned 199 responses from people in a wide range of age groups and occupations. Gender representation was effectively equal. In order to better appreciate the underlying design characteristics that may have influenced the responses, each of the six scenes was also rated in situ by the author, using the streetscape evaluation tool. These scores are listed in Table 1 with the scene scoring highest in each category highlighted.

\section{Visual preferences}

The scenes are a representative sample of the contextual relationships that can be expected to arise in contemporary cities, with detailed selection made to test situations of greatest interest to designers and regulators. Scene 6 was selected for the high sense of order it conveyed, as individual buildings share patterns of overall height, fenestration and architectural detailing above verandah level. Indeed, the only design characteristics that distinguish one building from the others are colour, frontage width and design features below verandah level. The scene was resoundingly preferred across the full range of design characteristics evaluated in this research and was rated a mean score of 4.07 for overall preference on a scale of 5. Using the streetscape rating tool, the visual-order score is based on the relationships of building heights (silhouette in Stamps' (2000) perceptual levels), façade modelling (form articulation) and element patterns (surface texture). Scene 6 achieves a relatively high score of 56 out of 70 possible. It would seem that people prefer harmonious relationships between tightly adjoining buildings, and a perceptible sense of order appears to be the primary visual attribute of well-liked places. The focus group was asked to elaborate on this and three primary factors emerged. First, the consistency of height leads to a settled appearance. Not only does this lead to a scene that is visually balanced and coherent, but positive meanings also attach to similarity in 
Table 1: Scores given to each of the six scenes against the five built-form characteristics on which aesthetic judgement is passed

\begin{tabular}{lccccc}
\hline $\begin{array}{l}\text { Aesthetic concept } \\
\text { Measured by }\end{array}$ & $\begin{array}{c}\text { Visual interest } \\
\text { Complexity }\end{array}$ & $\begin{array}{c}\text { Closure } \\
\text { Order }\end{array}$ & & \multicolumn{2}{c}{ Associational meanings } \\
\cline { 4 - 6 } & & & Human scale & Human activity & Cleanliness \\
\hline Scene 1 & $\mathbf{6 5}$ & 36 & 25 & 17 & 13 \\
Scene 2 & 35 & 44 & 21 & 19 & 15 \\
Scene 3 & 34 & 38 & 13 & 10 & 13 \\
Scene 4 & 23 & 28 & 22 & 11 & 24 \\
Scene 5 & 36 & 56 & 33 & 23 & 20 \\
Scene 6 & 29 & 70 & 50 & 30 & 30 \\
Max possible & 90 & &
\end{tabular}

height, equality and justice among them. As no one building seeks to stand out from the others in terms of height, form articulation or surface texture, a strong sense of equality and order is conveyed. Second, while the consistent fenestration pattern helps reinforce the sense of order across the scene it is also the most important generator of visual interest in the scene. Although the visual interest score is very low for Scene 6 this did not deter respondents from finding the group of buildings interesting. Designed as individual punched openings, the windows read as a visually powerful rhythm and it seems this is much more interesting than the large areas of glass found in the other scenes. Third, the focus group highlighted the importance of visually open and attractive ground floor shops. The positive responses were brought on by an awareness of building scale and understanding of how these spaces might be used. Several members of the focus group noted the positive associations they held for shopping as a leisure activity and this may have come into play while making their evaluations.

The research appears to confirm strong preference for Habraken's (1998) notion of backcloth buildings, where no one design stands out from the others, unless, for some respected reason, it deserves special treatment. Scene 6 presents a highly consistent relationship between adjacent buildings and is perhaps the closest model of Habraken's structure of ordinary forms that we can imagine today. The relationship of architectural styles in this scene was strongly preferred by the respondents. Scene 3 offers an interesting example of how thoughtful design has served to tie the scene together over an extended period of time. The block can be conceived as a series of successive interventions where each has served to reinforce the overall architectural imagery by way of consistent use of punched window openings, clearly articulated building outlines and muted surface treatments. Scene 3 reads coherently because of the way design threads have been pulled through the whole of the block over time. Scene 3 is considered to be a model for creating effective relationships between buildings by reinforcement of positive design attributes. It is also notable that none of these buildings stands out particularly from the others.

Contrast this with the variations in style presented in Scene 1. This scene exhibits many of the circumstances that occur in contemporary urban redevelopment, including wide frontage buildings as a result of site aggregation, shiny contemporary materials contrasting with older muted materials, large variations in building height and contrasting façade proportions. The public have voiced their displeasure with these relationships, with 55 per cent stating their dislike for it. When reasons for this were probed, the two most common responses were the poor fit of building ' $\mathrm{C}$ ' and of building ' $\mathrm{E}$ '. We can see that building ' $\mathrm{C}$ ' differs from its immediate neighbours in almost every respect, including complexity of silhouette, façade proportions and materiality. Built some years after building ' $\mathrm{C}$ ', building ' $E$ ' makes efforts to relate to the grain and proportions of its neighbours. Indeed, the design of this large hotel intervention adopts a number of commonly used strategies for contextual fit, including establishment of a brick-clad base that relates in height to its neighbours, breaking the form down into visually smaller elements by creating margins between them, window proportions drawing on the neighbouring buildings and stepping back the higher parts of the form by using visually lighter materials. In this case, the outcomes have not been judged to be successful. This design was noted to have the poorest fit with its setting of any in the survey. 
Not surprisingly, with the wide variety of styles, height and materials on show, Scene 1 was highly rated for visual interest by the streetscape assessment tool. However, this was coupled with an only average score for visual order. The notion that visually interesting schemes must be tempered by underlying order is only confirmed by these results. Close control of the height to which new development is allowed to extend would be one obvious message to design regulators. But it may not be as simple as this. It seems the public do generally prefer consistency in height between buildings; Scenes 2 and 6 are the most consistent in this area and they were highly rated for this characteristic by respondents. Scene 3 was also rated positively for the relationship of building heights. Although the heights do vary across this scene, the silhouette they cut is bold and graphic. Parapets are generally unadorned and the architectural styles and language provide the sense of consistency and order that is instrumental to positive visual experience. Building height is one of the important factors to control for when seeking to establish visual order across an urban street scene. However, it seems this could be relaxed in areas where other consistencies across the collection of buildings help establish the desired levels of order.

\section{Professional differences}

This research aims to identify differences, where they exist, in the aesthetic judgements of experts and the lay public. Earlier studies (Groat, 1994; Stamps, 1999; Fawcett and Ellingham et al, 2008) have returned mixed findings in this area of enquiry. For example, Stamps found that the views of architects and the public were aligned in some respects, but when architectural stimuli tended towards the unusual or avant-garde, differences in preference would arise. Groat consistently found that judgements around contextual compatibility differed between the groups and also that the criteria for judging differed. The public, she argued, were unwilling to consider any strategies other than visual continuity when evaluating the suitability of proposed interventions into an existing scene. Architects on the other hand were found to consider compatibility around other, perhaps deeper, aspects linking with history and meaning. This enables architects to be more accommodating of visual differences.
The first finding of this research is that architects and planners do, generally speaking, hold opinions similar to those of the lay public when appreciating complete urban street scenes. Although this differs with the earlier studies, there are several factors that may help explain why this is. The earlier studies sought preferences for single buildings, either on their own or in relation to the setting. This study is not focused in this way and instead seeks opinions about a group of buildings as a whole. Another key difference is that people were asked here to express preference for the relationships between the heights, styles and other design attributes within the scene. By not focussing on the attributes of a single building, and instead looking at relationships, it becomes easier to identify patterns where they exist. Architectural features and other matters that may lead to bias because of professional training are not factors when evaluating street scenes more broadly. This finding alone, that designers, planners and the lay public show similar preferences when judging the built environment, gives cause for optimism that places can be designed for broad appeal.

One of the few instances where lay and professional opinion differed was over Scene 4, a large-scale retailing development. Here, the designers have attempted to break down the scale of the project by first breaking it into two distinct halves and then modulating the façade in horizontal and vertical dimensions using architectural elements such as columns, windows and overhangs. With nearly a quarter of the lay respondents indicating a neutral opinion, the rest were equally split into the positive and negative categories. Architects and planners, on the other hand, were quite negative about it, with upwards of 68 per cent registering their displeasure. It emerged that a principal reason for this was a perception that traditional elements, such as windows as in the upper floors and a top-level terrace, were employed dishonestly in the design. There were also concerns raised about the scale of the building and how the design made use of visual trickery in attempts to bring the building into a more human scale. These matters were not of concern to lay respondents, and indeed several suggested the scene to be pleasant because of the association with shopping. The differences noted in respect of this one scene recalls the views of Rapoport (1982), who advises that lay people are more prone to evaluate their surroundings in associational terms whereas designers are known 
to respond in perceptual terms, as their meanings lay in the composition. In the case of Scene 4, the professionals clearly spotted a fraud.

Further analysis reveals that there are significant differences in the strength and conviction of the opinions expressed by the three professional groupings. Architects tend to be more demonstrative in their views, with a greater percentage of their responses extending into both ends of the 5-point scale. An example of this is the responses to Scene 1 . Here 48 per cent of the lay public, 56 per cent of architects and 42 per cent of planners found the scene to be either very or somewhat unpleasant. On closer inspection, 30 per cent of architects found the scene to be very unpleasant whereas only 12 per cent and 9 per cent, respectively, of the lay public and planners found it to be so. The data consistently revealed this tendency and they suggest that designers are more confident in their expression of design and compositional matters.

On the other hand, planners appear to be more reticent in expressing their views. Very small numbers of planners made use of the top or bottom values on the rating scale, compared even with the lay public. Coupled with this was a tendency for scores to be bunched on the neutral scoring mark. The results give an impression that members of the planning profession are ambivalent when offering their views on the built environment. Rather than ambivalence, the likely cause is an underlying tendency towards risk avoidance. With increasing complexity of environmental issues, land-use planning is rapidly becoming a discipline that simply organises and presents the expert views of others in proposals and assessments. Accordingly, the need for planners to express their own expert opinions across a range of areas is diminishing. Aesthetic judgement may be one of those areas. Planners, particularly those responsible for controlling development on behalf of local authorities, also operate around highly contentious decisions that are never likely to please all stakeholders. The finding that planners are reticent when expressing their preferences may reflect diminishing confidence levels and tendencies to avoid risk by working close to the neutral point.

\section{Conclusions}

It appears that the public has discerning tastes when it comes to the built environment. After considering a variety of streetscape stimuli, respondents were overwhelmingly positive about scenes that are visually ordered. The most positively rated scene featured consistency and perceptual closure on the three levels at which urban street scenes are perceived: silhouette, form articulation and surface texture. However, opportunities to create such a consistent collection of buildings would indeed be rare in today's development context. It can be expected that differences in building height and external cladding material will arise, at the very least. Even where these differences occur between adjacent buildings the public will rate the streetscape positively where other, underlying patterns are seen to extend across the block. This research has found that strongly articulated patterns of fenestration, clear and graphic silhouette outlines and similarities of surface texture can provide the necessary sense of order that will lead to positive visual experience. The research has also found there to be strong resistance to scenes that are highly varied and in which there is no underlying sense of order. These are perhaps the types of settings referred to when other researchers describe the displeasure that the public finds with the visual appearance of the built environment. It would appear that the design of new interventions should be informed not only of an awareness of the characteristics of the immediately adjacent buildings, but also of the entire block in which the site is situated. The goal should be to become aware of patterns, where they exist, that help order the whole scene even when the architectural details differ. New interventions should seek to extend and reinforce these patterns to help ensure a favourable aesthetic response.

The research also evaluated the aesthetic preferences of architects, town planners and the lay public to understand differences where they exist. Overall, preferences for and dislike for particular visual characteristics are expressed similarly between the groups. However architects are more demonstrative in their views and prone to be more critical where learned architectural conventions have not been followed. This finding is encouraging and suggests that as we all have similar underlying visual preferences it should be possible for places to change in ways that find favour with the majority of people. Unfortunately, and despite evidence that visual preferences among lay and professional people are aligned, we have come to understand that preferences 
are different when they are expressed in a professional context. This is an indication of how culture, in this case professional, can influence or create bias in aesthetic judgement. Nevertheless, it may be possible to work on professional bias with reference to the findings presented here. For if the influence of professional culture on visual preferences, which as we have learned encourages designs that make strong statements, can be diminished in favour of the underlying aesthetic preferences that are common among lay people and professionals, then there is hope that new buildings can be created that work with and contribute to the overall setting.

\section{References}

Alcock, A. (1993) Aesthetics and urban design. Making Better Places: URBAN DESIGN Now, In: S. McGlynn and R. Hayward (eds.) Oxford: Butterworth Architecture, p. 147. Bentley, I. (1999) Urban Transformations: Power, People And URBAN DESIGN. London: Routledge.

CABE. (2006) Design Review. UK: Commission for Architecture \& the Built Environment, p. 24.

Carmona, M., Heath, T., Oc, T. and Tiesdell, S. (2010) Public Places Urban Spaces. Oxford, UK: Architectural Press; Elsevier.

Carmona, M. and Tiesdell, S. (eds.) (2007) URBAN DESIGN Reader. Oxford, UK: Architectural Press.

Cuthbert, A.R. (2006) The Form of Cities, Political Economy and URBAN DESIGN. Oxford, UK: Blackwell Publishing.

Dovey, K. (2001) The aesthetics of place. In: B. Cold (ed.) Aesthetics, Well-being and Health. Aldershot, UK: Ashgate Publishing, pp. 93-101.

Fawcett, W., Ellingham, I. and Platt, S. (2008) Reconciling the architectural preferences of architects and the public: The ordered preference model. Environment and Behaviour 40(5): 599-618.

Groat, L. (1988) Contextual compatibility in architecture: An issue of personal taste? In: J.L. Nasar (ed.) Environmental Aesthetics: Theory, Research and Applications. Cambridge: Cambridge University Press, pp. 228-257.
Groat, L.N. (1994) Carbuncles, columns and pyramids: Lay and expert evaluations of contextual design Strategies. B.C. Scheer and W.F.E. Preiser (eds.) Design Review: Challenging Urban Aesthetic Control. New York: Chapman \& Hall, pp. 156-164.

Habraken, N.J. (1994) Cultivating the field: About an attitude when making architecture. Places 9(1): 8-21.

Habraken, N.J. (1998) Structure of the Ordinary. Cambridge, MA: The MIT Press.

Jacobs, J. (1961) The Death and Life of Great American Cities. New York: Random House.

Lynch, K. (1960) The Image of the City. Cambridge, MA: MIT Press.

Nasar, J.L. (1994) Urban design aesthetics: The evaluative qualities of building exteriors. Environment and Behaviour 26(3): 377-401.

Nasar, J.L. (1998) The Evaluative Image of the City. Thousand Oaks, CA: Sage Publications.

Portella, A.A. (2007) Evaluating commercial signs in historic streetscapes. PhD thesis, Joint Centre for URBAN DESIGN, Oxford Brookes University, Oxford, UK.

Punter, J. (1999) Improving the instruments processes and products of aesthetic control in Europe. URBAN DESIGN International 4(1\&2): 79-99.

Rapoport, A. (1982) The Meaning of the Built Environment: A Nonverbal Communication Approach. Beverly Hills, CA; London: Sage.

Rapoport, A. and Kantor, R.E. (1967) Complexity and ambiguity in environmental design. Journal of the Institute of American Planners 33: 210-221.

Reeve, A., Goodey, B. and Shipley, R. (2007) Townscape assessment: The development of a practical tool for monitoring and assessing visual quality in the built environment. Urban Morphology 11(1): 25-41.

RFAC. (1994) What Makes a Good Building?: An inquiry by the Royal Fine Art Commission. London: Royal Fine Art Commission.

Sanoff, H. (1991) Visual Research Methods in Design. New York: Van Nostrand Reinhold.

Smith, P.F. (1977) The Syntax of Cities. London: Hutchinson.

Stamps, A.E. (1999) Demographic effects in environmental aesthetics: A meta-analysis. Journal of Planning Literature 14: $155-175$

Stamps, A.E. (2000) Psychology and the Aesthetics of the Built Environment. Dordrecht, The Netherlands: Kluwer Academic Publishers Group. 